\title{
Inflammatory and Necrotic Effects of Minodronate, a Nitrogen-Containing Bisphosphonate, in Mice
}

\author{
Tomomi Kiyama, ${ }^{1,2}$ Satoru Okada, ${ }^{1,3}$ Yukinori Tanaka, ${ }^{1}$ Siyoung Kim, ${ }^{1,4}$ \\ Kanan Bando, ${ }^{1,4}$ Masakazu Hasegawa, ${ }^{4}$ Kouji Yamaguchi, ${ }^{1,3}$ \\ Teruko Takano-Yamamoto, ${ }^{4}$ Keiichi Sasaki, ${ }^{2}$ Shunji Sugawara ${ }^{1}$ and Yasuo Endo ${ }^{1}$

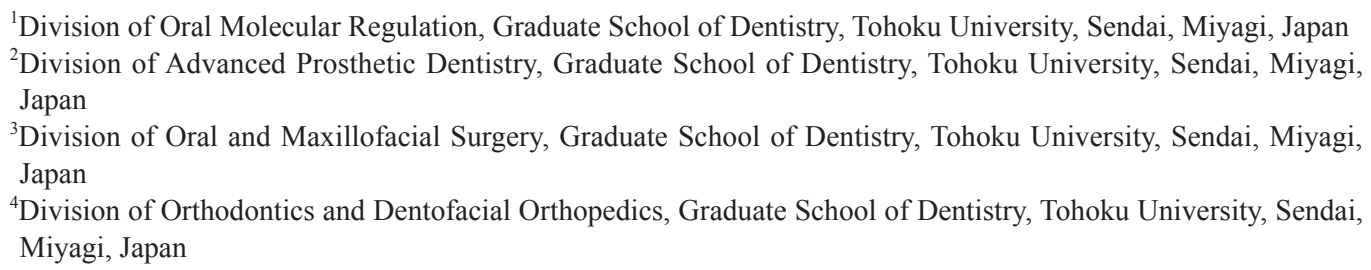

Diseases involving enhanced bone-resorption (e.g., osteoporosis) are widely treated with bisphosphonates (BPs). BPs are of two types: the nitrogen-containing BPs (N-BPs) and the non-nitrogen-containing BPs (non-N-BPs). N-BPs have much stronger anti-bone-resorptive effects than non-N-BPs, and N-BPs can exert inflammatory and necrotic effects, including osteonecrosis of jawbones. Minodronate, an N-BP, was approved in 2009 in Japan for osteoporosis. Its anti-bone-resorptive effect is comparable to that of zoledronate, the N-BP with the strongest anti- bone-resorptive effect and the highest risk of side effects yet reported. Unlike other N-BPs, minodronate has an analgesic effect, and no serious side effects have been documented. Here, to examine whether minodronate lacks inflammatory and/or necrotic effects, we used mice (since the N-BPs tested so far induce such effects in mice with potencies that parallel those reported in humans). To facilitate comparison with previous studies, we gave a single systemic (intraperitoneal) or local (ear pinna) injection of minodronate (or another N-BP). We measured the systemic responses (weight of thoracic exudate, number of inflammatory cells in the peritoneal cavity, and spleen weight) or local responses (area of inflamed skin and incidence of necrosis). Anti-bone-resorptive effects were evaluated by X-ray analysis of tibias following intraperitoneal injection. Minodronate's anti-bone-resorptive effect and its inflammatory and necrotic effects were as great as, or greater than those of zoledronate. Moreover, in cultured human periodontal ligament cells, the cytotoxicity of minodronate was significantly greater than that of zoledronate. These results suggest that caution may be needed with minodronate in clinical use, as with other N-BPs.

Keywords: bisphosphonates; inflammation; minodronate; osteonecrosis; osteoporosis

Tohoku J. Exp. Med., 2013 July, 230 (3), 141-149. C 2013 Tohoku University Medical Press

\section{Introduction}

Osteoporosis is the most frequently encountered disease in middle- and old-age in women, and its prevention and treatment are matters of concern worldwide, especially in countries experiencing population aging (Chen and Sambrook 2012). Bisphosphonates (BPs) are the current first-choice drugs for various diseases associated with enhanced bone resorption, including osteoporosis and bone metastases (Roelofs et al. 2006; Neville-Webbe and Coleman 2010). A number of BPs have been synthesized, and among them the BPs with a nitrogen-containing side chain (called N-BPs) have anti-bone-resorptive effects
(ABREs) that are much more powerful than those of nonnitrogen-containing BPs (non-N-BPs) (Roelofs et al. 2006). Unfortunately, use of N-BPs, especially intravenous use, is associated with a risk of osteonecrosis of jawbones (ONJ), a serious condition that usually presents as areas of exposed maxillofacial bone that prove resistant to healing (Adami and Zamberlan 1996; Ruggiero et al. 2004; Woo et al. 2006). These lesions of jawbones are traumatic for the patient, as well as for the dentist.

Among the N-BPs approved for clinical use so far, zoledronate has the most potent ABRE (Roelofs et al. 2006) (Fig. 1), and it also carries the highest risk of ONJ (Woo et al. 2006). In addition to ONJ, N-BPs have other side

Received February 20, 2013; revised and accepted June 12, 2013. Published online July 2, 2013; doi: 10.1620/tjem.230.141.

Correspondence: Yasuo Endo, Department of Oral Molecular Regulation, Graduate School of Dentistry, Tohoku University, 4-1 Seiryomachi, Sendai, Miyagi 980-8575, Japan.

e-mail: endo@dent.tohoku.ac.jp 


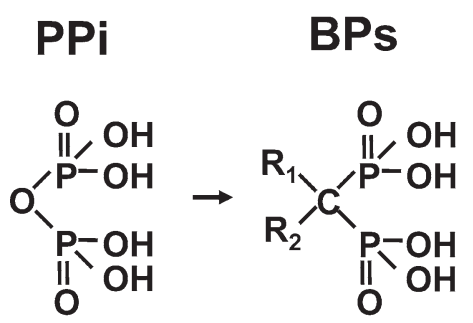

Alkyl N-BPs
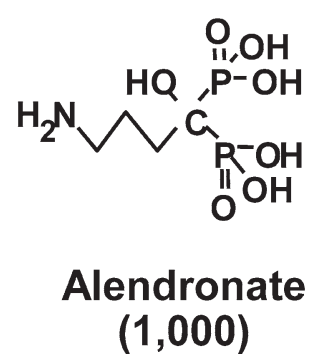<smiles>CC(O)(P(=O)(O)O)P(=O)(O)O</smiles>

Etidronate (1.0)
Non-N-BPs<smiles>O=P(O)(O)C(Cl)(Cl)P(=O)(O)O</smiles>

Clodronate

(3.3)

Heterocyclic N-BPs<smiles>O=P(O)(O)C(O)(Cn1ccnc1)P(=O)(O)O</smiles>

Zoledronate
$(10,000)$

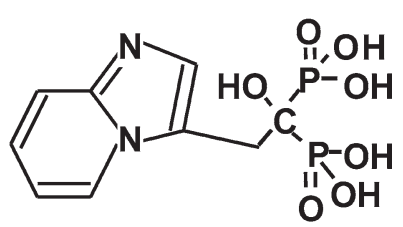

Minodronate
$(10,000)$

Fig. 1. Structures of BPs used in the present study and their relative ABREs. For each BP, the ABRE is expressed relative to that of etidronate, which is shown as 1 (Geddes et al. 1994).

effects, including hyperthermia and direct injuries to esophageal and gastric tissues (Adami et al. 1987; Adami and Zamberlan 1996). N-BPs display cytotoxic effects against various types of cells, including osteoclasts, via intracellular inhibition of farnesyl pyrophosphate synthase, which is involved in cholesterol biosynthesis (Roelofs et al. 2006; Rogers et al. 2011).

In Japan, more than 500 patients with N-BP-related osteomyelitis and/or ONJ were recorded up to 2008 (Urade 2010). Those were the circumstances in which minodronate was approved for use in Japan (from April 2009) as a new N-BP for osteoporosis. Minodronate, like zoledronate, belongs to the heterocyclic N-BPs (Fig. 1). Interestingly, minodronate reportedly displays an ABRE-independent analgesic effect via its antagonism of the purinergic $\mathrm{P}_{2 / 3}$ receptor (Kakimoto et al. 2008), although such an analgesic effect has not been reported for other N-BPs. In addition, minodronate-related cases of ONJ are absent from the literature (Hagino et al. 2011; Okazaki et al. 2011), and it apparently has no gastrointestinal adverse effects (Hagino et al. 2011; Okazaki et al. 2011). Thus, minodronate would be expected not to cause traumatic lesions of jawbones, such as those associated with other N-BPs. Incidentally, most patients with osteoporosis receive N-BPs and non-N-BPs orally. ONJ can occur following either oral or intravenous administration of N-BPs, although the latter cases are much more frequent. Concerning minodronate and zoledronate, the former is orally administered to patients with osteoporosis, while the latter is intravenously administered to patients with bone-metastatic cancers.

BPs (irrespective of whether they are N-BPs or non-N-
BPs) bind strongly to bone hydroxyapatite and accumulate within the bone upon repeated administration. Further, it is thought that an N-BP that has accumulated within a jawbone may be released during and/or after injury or destruction of that bone (e.g., due to tooth extraction and/or infection), and that the released N-BP may directly injure the surrounding soft tissues (Yamaguchi et al. 2010). Indeed, (i) zoledronate can be detected in the saliva of patients who have been treated with zoledronate (Scheper et al. 2009), (ii) as described above, N-BPs directly injure esophageal and gastric tissues, (iii) when injected topically in mice, N-BPs induce inflammation and necrosis at the injection site with potencies that nearly parallel those of their ABREs (Schenk et al. 1986; Oizumi et al. 2009), and (iv) the potencies with which N-BPs induce their inflammatory and necrotic side effects (INSEs) in mice seem to parallel those reported in human patients (Oizumi et al. 2009). These findings suggest that for N-BPs, the potential to induce INSEs in animal experiments (see above) correlates with their clinical potential to cause INSEs (including ONJ). N-BPs, when injected intraperitoneally into mice, induce a number of inflammatory reactions. These include prolonged induction of the histamine-forming enzyme histidine decarboxylase, pleural exudation, an increase in granulocytic cells in the peritoneal cavity, splenomegaly, hypoglycemia, and accumulation of IL- $1 \beta$ in various tissues (Endo et al. 1993, 1999; Deng et al. 2006).

Clodronate is a non-N-BP. Non-N-BPs are converted directly into cytotoxic ATP-analogs within cells (Roelofs et al. 2006; Rogers et al. 2011). It is notable both that ONJ cases are very scarce in patients treated with clodronate 
(Crépin et al. 2010), and that clodronate does not induce acute inflammatory side effects in human patients (Adami et al. 1987). Thus, it is questionable whether clodronate does indeed cause ONJ. In mice, not only is clodronate devoid of INSEs such as those described above, but its coadministration with an N-BP can reduce or prevent the INSEs of the N-BP without affecting the latter's ABRE (Endo et al. 1999; Oizumi et al. 2009; Shikama et al. 2010). On that basis, we proposed elsewhere that (i) clodronate could be valuable as a combination drug for use with N-BPs (to prevent their necrotic actions while retaining their ABREs) and (ii) clodronate could also be useful as a substitution drug for N-BPs in patients at high risk of osteonecrosis of the jawbones (Monma et al. 2004; Oizumi et al. 2009).

From the evidence described above, it is possible that INSEs are intrinsic to all N-BPs. However, minodronate evidently lacks some of the side effects associated with other N-BPs. We therefore examined its INSEs (and also its ABRE) in mice, and compared them with those of other N-BPs, especially with those of zoledronate. This would be expected to yield clinically relevant information since the potential of N-BPs to induce INSEs in animal experiments correlates with their clinical potential to cause INSEs (see above). We administered N-BPs intraperitoneally or topically to facilitate comparison with previous studies on the INSEs of N-BPs in mice and rats, most of which have involved administration by those two routes (with only a few studies using oral administration). For the in vivo experiments, we used doses of these reagents similar to those employed in our previous studies, described above. Then, since minodronate was found to cause INSEs in those experiments, we looked for evidence of modulating effects of clodronate on the INSEs and ABRE of minodronate. Additionally, in an in vitro study, we compared the cytotoxicities of minodronate and zoledronate.

\section{Materials and Methods}

\section{Mice and reagents}

If not otherwise mentioned, female BALB/c mice (7-8 weeks old) bred in our laboratory were used in this study. Homozygous BALB/c IL-1KO mice (deficient in both IL-1 and IL-1 $\beta$ ) were provided by Dr. Y. Iwakura (University of Tokyo, Tokyo, Japan) (Horai et al. 1998). All experiments complied with the Guidelines for Care and Use of Laboratory Animals in Tohoku University. Minodronate was synthesized for basic studies by Chengdu D-Innovation Pharmaceutical Co., Ltd (Chengdu, China). Zoledronate and clodronate were from Toronto Research Chemicals Inc. (North York, ON, Canada) and Sigma (St. Louis, MO, USA), respectively. The above drugs were dissolved in sterile saline, with the $\mathrm{pH}$ of the solutions being adjusted to 7 with $\mathrm{NaOH}$. Experimental protocols are described in the text or in the legend to the Figure relating to each experiment.

\section{Estimation of the ABREs of BPS}

A clear sclerotic band (tentatively called the BP-band) is detectable in tibias by radiography a few weeks after a single injection of a BP into mice (Fig. 2), reflecting an inhibition of bone resorption

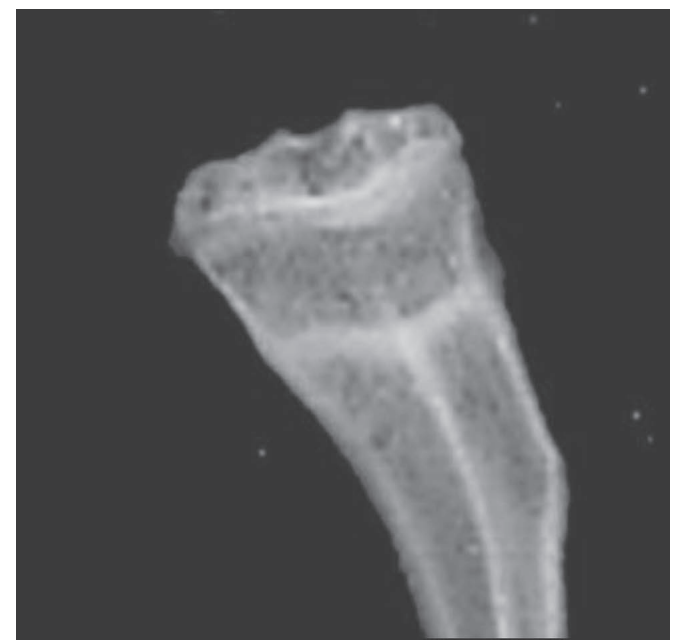

Fig. 2. BP-band, as used for the estimation of the ABREs of BPs. A single injection of a BP into young mice produces a clear sclerotic band, the "BP-band", that is detectable in tibias by radiography a few weeks after the injection. This band reflects inhibition of bone resorption. The BP-band shown in this figure was one that was evident at 3 weeks after a single intraperitoneal injection of alendronate $(1.6 \mu \mathrm{mol} / \mathrm{kg})$ into a 5 -week-old female mouse.

(Monma et al. 2004; Funayama et al. 2005; Yu et al. 2005). Hence, we estimated the ABREs of NBPs by using the BP-band as a marker. Briefly, each N-BP solution was intraperitoneally injected into young (5-week-old) female mice $(0.1 \mathrm{ml} / 10 \mathrm{~g}$ body weight). The mice were decapitated three weeks later, and tibias were removed and subjected to X-ray analysis for the detection of the BP-band, as previously described (Oizumi et al. 2009). The tibias were also subjected to micro-computed tomography (micro-CT) analysis for the quantification of the BP-band using a CT apparatus for experimental animals (LATHETA $^{\mathrm{TM}}$, LCT-200; ALOKA Corp., Tokyo, Japan) and OnDeman3D Application software (Cybermed Co., Seoul, Korea). The area of each BP-band was measured in the vertical section of the tibia displaying its maximal length.

Evaluation of the systemic INSEs induced by intraperitoneally injected $N$-BPS

(1) Exudate in thorax. After the thorax had been opened with scissors, the exudate present in the thorax was absorbed using small pre-weighed pieces of filter paper and the amount of exudate was measured as the increase in the weight of the filter paper.

(2) Cell count in peritoneal cavity. Peritoneal-exudate cells were obtained as follows. Sterile saline $(10 \mathrm{ml})$ was injected into the peritoneal cavity of ether-anesthetized and decapitated mice, and the cavity was massaged. Then, the suspension of cells in the saline (5 $\mathrm{ml}$ ) was recovered using a syringe, and the number of cells in the suspension was counted after appropriate dilution.

(3) Blood glucose. A segment of the tail vein was pierced with a needle, and the blood extruded (about $5 \mu$ ) was directly applied to a strip so that glucose could be determined (by a method based on the glucose-dehydrogenase method) using a glucometer (Accu-Chek Advantage; Roche Diagnostics K.K., Tokyo, Japan). 
Evaluation of the local INSEs of topically injected $N$-BPS

Mice (7-8 weeks of age) were anesthetized with ethyl ether, and an N-BP solution was injected subcutaneously into both the right and the left pinna (inside) near the root of the ear (20 $\mu$ l each ear) (4 mice/ group). The concentrations used are indicated in the relevant experiments. The inflammatory and necrotic actions of N-BPs were evaluated daily as described below (Oizumi et al. 2009). All experiments were terminated on day 7 .

(a) Inflammation: The length (L) and width (W) of the area of inflammation at the back of the ear (detectable as a red area) were recorded, and $\mathrm{L} \times \mathrm{W}\left(\mathrm{mm}^{2}\right)$ was used as an indicator of inflammation.

(b) Necrosis: After maximum inflammation (estimated as described above) had been attained, the center of the inflammatory site became necrotic [detectable as a change of color from red to dark brown (or black) or as a tissue defect]. At the start of the necrosis, we stopped measuring inflammation, and in each group of mice we recorded the number of ears with and the number without necrosis [expressed as the incidence of necrosis (e.g., maximum incidence is 8 in a group of 4 mice)].

\section{In vitro cytotoxicity}

Human periodontal ligament (HPDL) cells were kindly provided by Dr. E. Nemoto (Tohoku University, Sendai, Japan) (Nemoto et al. 2005). Cells were grown in MEM $\alpha$ supplemented with $10 \%$ FCS at $37^{\circ} \mathrm{C}$ in a humidified atmosphere containing $5 \% \mathrm{CO}_{2}$. Cells were seeded in 96-well flat-bottomed plates at $5 \times 10^{3}$ cells $/ 100 \mu \mathrm{l} /$ well and were allowed to adhere overnight. Then, the medium was removed from the cells and replaced with fresh culture medium (100 1/well) with or without one or more BPs (see text or legends to Figures). After culture had proceeded for 48 or $72 \mathrm{~h}, 10 \mu \mathrm{l}$ of WST-8 (2-[2-methoxy-4-nitrophenyl]-3-[4-nitrophenyl]-5-[2,4-disulfophenyl]-2H-tetrazolium monosodium salt) solution (Cell Counting Kit-8; Dojindo Co. Ltd., Kumamoto, Japan) was added to each well. The amount of formazan formed by the action of mitochondrial dehydrogenases in vital cells was determined spectrophotometrically at $450 \mathrm{~nm}$. Cell viability was evaluated by taking the difference in absorbance values between the control (without BPs) and test groups and expressing it as a percentage of that of the control group.

\section{Statistical analysis}

Experimental values are given as the mean standard deviation (S.D.). The statistical significance of differences was analyzed using a two-way analysis of variance (ANOVA) followed by a Bonferroni post hoc multiple-comparison test (Prism 4 software; GraphPad Software Inc., San Diego, CA, USA). For differences in incidence between two experimental groups at a given time-point, analysis was by the Fisher exact probability test (Instat software; GraphPad Software Inc., La Jolla, CA, USA). $P$ values less than 0.05 were considered to indicate significance.

\section{Results}

ABRE of minodronate, alone or in combination with clodronate

From the literature, the relative potencies with which minodronate, zoledronate, and alendronate induce ABREs are approximately 10:10:1 (Fig. 1). As shown in Fig. 3A,

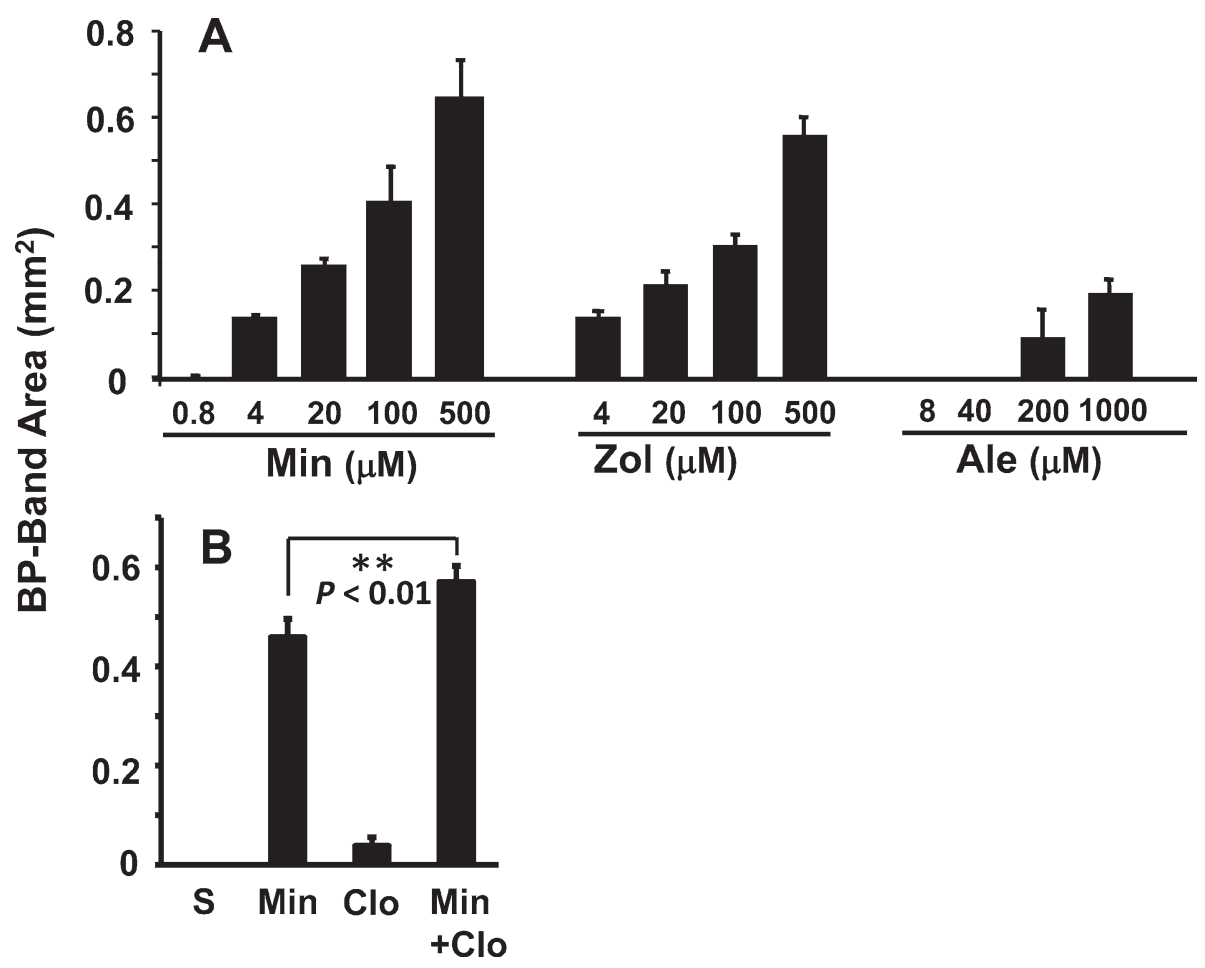

Fig. 3. ABRE of minodronate. (A) Comparison of the ABREs of minodronate (Min), zoledronate (Zol), and alendronate (Ale). The indicated doses of the N-BPs were intraperitoneally administered to mice, and the resulting tibial BP-bands were analyzed (see Methods). (B) ABREs induced by Min and/or Clo. Saline, Min $(0.2 \mu \mathrm{mol} / \mathrm{kg})$, Clo $(2.0 \mu \mathrm{mol} / \mathrm{kg})$, or a combination $(\mathrm{Min}+\mathrm{Clo})$ was given to mice, and 3 weeks later their tibial BP-bands were analyzed. Each value represents the mean \pm S.D. $(n=4)$. 
the rank order of potencies for the formation of a BP-band in our mice was minodronate $\geq$ zoledronate $>$ alendronate. Thus, the ABRE of minodronate is greater than that of alendronate and comparable to or greater than that of zoledronate.

We have previously shown in mice that the ABRE induced by co-injection of clodronate with either alendronate or zoledronate is similar to or greater than that of alendronate alone or zoledronate alone (Monma et al. 2004; Oizumi et al. 2009). In the present study, as shown in Fig. $3 \mathrm{~B}$, following co-injection of clodronate with minodronate the ABRE was significantly stronger than that produced by minodronate alone.

\section{Inflammatory effects of intraperitoneally administered} minodronate, alone or co-administered with clodronate

As reported previously, a single intraperitoneal injection of an N-BP (alendronate, incadronate, or ibandronate, each $40 \mu \mathrm{mol} / \mathrm{kg}$ ) induces various inflammatory reactions, and the reactions are greatly reduced by co-administration of $160 \mu \mathrm{mol} / \mathrm{kg}$ of clodronate (Endo et al. 1999). As shown in Fig. 4A, zoledronate and minodronate, at $20 \mu \mathrm{mol} / \mathrm{kg}$, each induced inflammatory and other reactions, including decreases in body weight and blood glucose, and increases in the exudate in the thorax, in the number of inflammatory cells in the peritoneal cavity, and in spleen weight. Apart from the splenomegaly, such reactions to zoledronate injection were largely inhibited by co-injection of $160 \mu \mathrm{mol} / \mathrm{kg}$ of clodronate. The reactions induced by minodronate, except for the splenomegaly and the increase in peritoneal cells, were inhibited by co-injection of $160 \mu \mathrm{mol} / \mathrm{kg}$ of clodronate, too. The minodronate-induced splenomegaly and increase in peritoneal cells were significantly reduced by a higher dose $(320 \mu \mathrm{mol} / \mathrm{kg})$ of clodronate (data not shown). These results also suggest that (i) like zoledronate, minodronate is inflammatory in nature, and the latter's inflammatory effect is comparable to or greater than that of zoledronate, and (ii) the inflammatory effect of minodronate, like that of zoledronate, can be decreased or prevented by co-administration of clodronate.

\section{Inflammatory effect of intraperitoneally administered mino- dronate in IL-1-KO mice}

We previously reported that the inflammatory effects of N-BPs (alendronate, incadronate, and ibandronate; each at $40 \mu \mathrm{mol} / \mathrm{kg}$ ) were weak or undetectable in IL-1-KO mice (Yamaguchi et al. 2000). As shown in Fig. 4B, the inflammatory effects (except for splenomegaly) of zoledronate and minodronate were also significantly weaker in IL-1-KO mice than in control WT BALB/c mice.

INSEs induced by subcutaneous injection of minodronate or zoledronate into ear pinnas, and the modulating effects of clodronate

A single subcutaneous injection of an N-BP into ear pinnas $(20 \mu \mathrm{l} / \mathrm{ear})$ induces inflammatory and/or necrosis in the ear pinna itself. The reported relative potencies for the necrotic effect are zoledronate $>>$ pamidronate $\geq$ alendronate $>$ risedronate, and the potent necrotic effect of zoledronate $(4 \mathrm{mM})$ is reduced by clodronate in a dose-dependent manner (completely prevented by clodronate at $4 \mathrm{mM}$ or more) (Oizumi et al. 2009). As shown in Fig. 5A, $2 \mathrm{mM}$ minodronate also induced such inflammatory and necrotic effects in ear pinnas, and the effects of minodronate were significantly greater than those of zoledronate. Like those of zoledronate (see above), the inflammatory and necrotic effects of minodronate were almost completely prevented by co-injection of $10 \mathrm{mM}$ clodronate (Fig. 5B).

In vitro cytotoxic effect of minodronate, and the modulating effect of clodronate

Both minodronate and zoledronate had cytotoxic effects on HPDL cells at $1 \mu \mathrm{M}$ or more (Fig. 6), and this effect was more profound after incubation for $72 \mathrm{~h}$ than after $48 \mathrm{~h}$. The cytotoxic effect of minodronate was significantly stronger than that of zoledronate at the concentrations indicated in Fig. 6.

\section{Discussion}

\section{Summary of the findings}

The ABRE of minodronate was comparable to or greater than that of zoledronate. However, minodronate, like other N-BPs, had INSEs, and its potency in inducing these INSEs was also comparable to or greater than that of zoledronate. The INSEs of minodronate, like those of other N-BPs: (a) were reduced or prevented by co-administration of clodronate (a non-N-BP) and (b) were weak in mice deficient in IL-1. These findings are discussed in the following paragraphs.

\section{ABRE of minodronate}

BPs are taken up by osteoclasts during bone resorption, and thereby exhibit their ABREs (Geddes et al. 1994; Roelofs et al. 2006; Rogers et al. 2011). N-BPs have cytotoxic effects in vitro on osteoclasts, as well as on various other cell-types, via intracellular inhibition of farnesyl pyrophosphate synthase (FPP-synthase; an enzyme involved in cholesterol biosynthesis). This leads to (i) the conversion of isoprenoid intermediates to cytotoxic ATP analogues and (ii) reduced prenylation of the small GTPase signaling proteins required for cell functions. On the other hand, non-N-BPs are converted into cytotoxic ATP analogues within cells (Frith et al. 2001; Roelofs et al. 2006; Räikkönen et al. 2009; Rogers et al. 2011). It was reported that the inhibitory effect of minodronate on FPP-synthase is comparable in size to that of zoledronate, the N-BP with the most powerful ABRE and highest ONJ risk yet reported (Roelofs et al. 2006). Thus, the present finding that the ABRE of minodronate (as evaluated by BP-band analysis in mouse tibias) is comparable to or rather greater than that of zoledronate may indicate that the former is as potent, or more potent, than the latter at inhibiting FPP-synthase. 
A

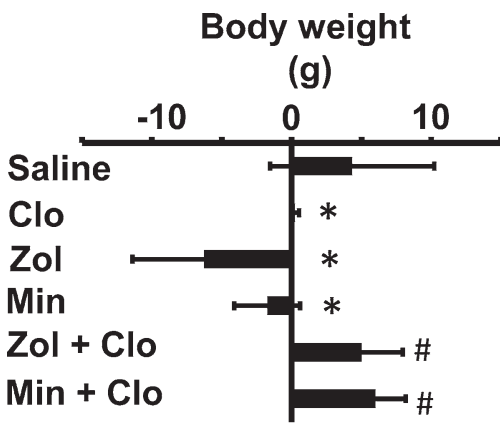

Spleen weight

(mg)
Blood glucose (mg/dl)

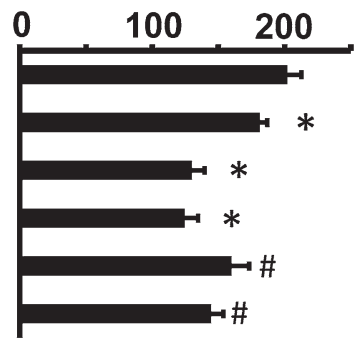

Cells in

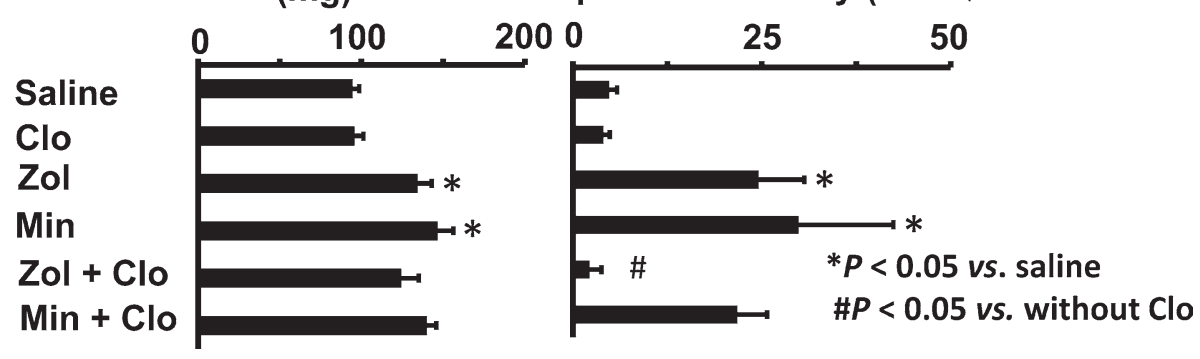

B
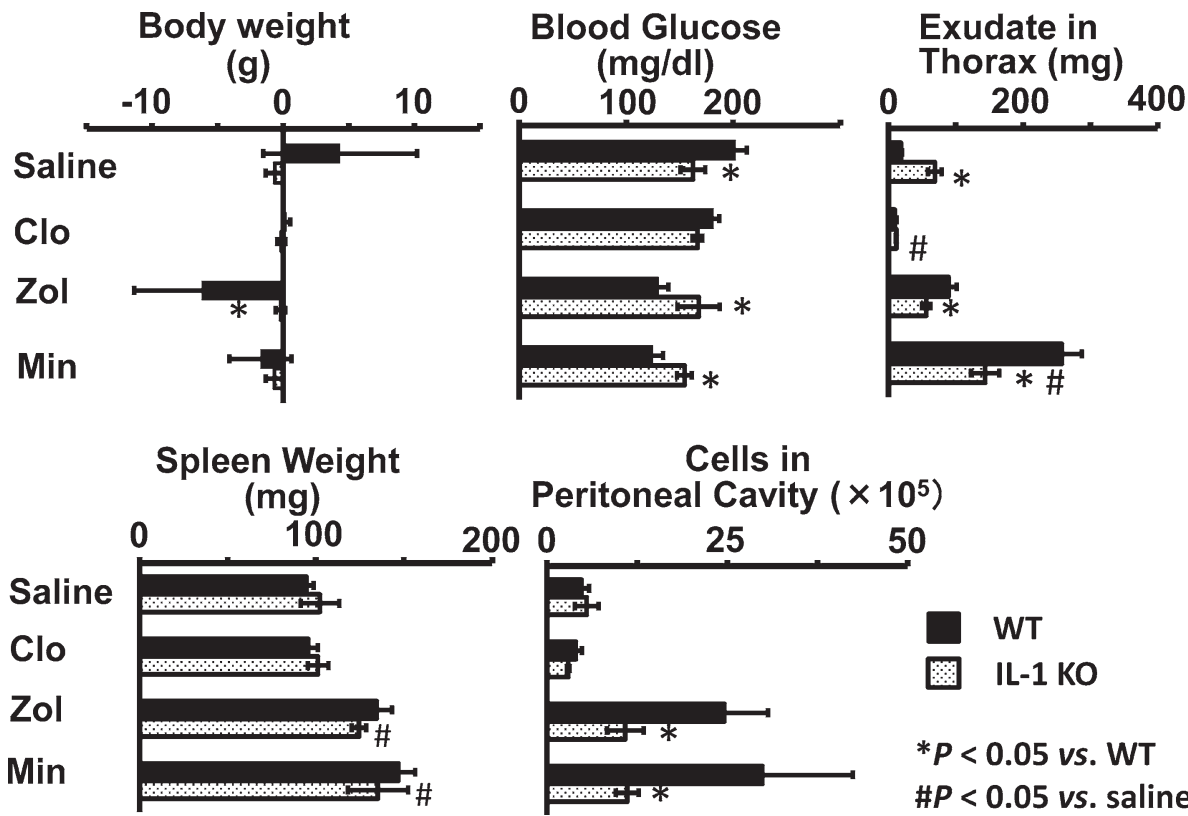

Cells in Peritoneal Cavity $\left(\times 10^{5}\right)$

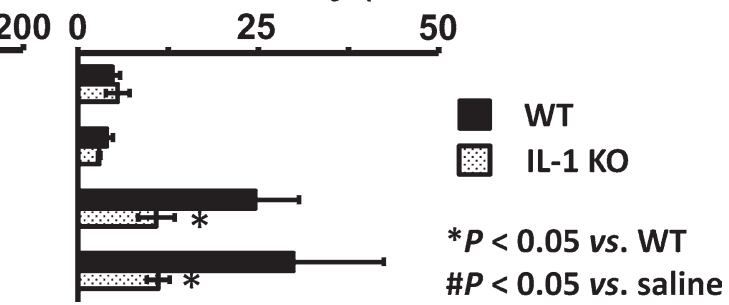

Fig. 4. Inflammatory reactions induced by intraperitoneal injection of minodronate, and the modulating effect of clodronate. Saline, minodronate (Min, $20 \mu \mathrm{mol} / \mathrm{kg}$ ), zoledronate $(\mathrm{Zol}, 20 \mu \mathrm{mol} / \mathrm{kg}$ ), or clodronate $(\mathrm{Clo}, 160 \mu \mathrm{mol} / \mathrm{kg}$ ), or one of the combinations Min + Clo or Zol + Clo, was intraperitoneally injected into wild-type (WT) BALB/c or IL-1-KO mice. Three days later, body weight, blood glucose, exudate in thorax, spleen weight, and cell count in the peritoneal cavity were measured. Each value represents the mean \pm S.D. $(n=4)$. (A) Effects in WT BALB/c mice. (B) Comparisons between WT BALB/c and IL-1-KO mice for the above effects.

\section{INSEs of minodronate in mice and in humans}

In clinical use, minodronate and zoledronate are administered orally and intravenously, respectively [minodronate at $1 \mathrm{mg} /$ patient daily or $50 \mathrm{mg} /$ patient every 4 weeks; zoledronate at $4 \mathrm{mg} /$ patient every 3-4 weeks, $100 \mathrm{ml}$ diluted solution being injected slowly (taking more than 15 $\min )]$. Thus, we cannot directly compare the doses given in the present study to those in clinical use (although the doses used in the present experiments were larger than those used in humans in $\mathrm{mg} / \mathrm{kg}$ terms). However, we previously suggested that patients might be more sensitive than mice to the inflammatory actions of N-BPs (Yamaguchi et al. 2000), because single clinical (intravenous) doses of N-BPs (pamidronate, alendronate, or zoledronate) are sufficient to produce inflammatory responses, such as fever, acute phase responses or serum elevation of proinflammatory cytokines. 

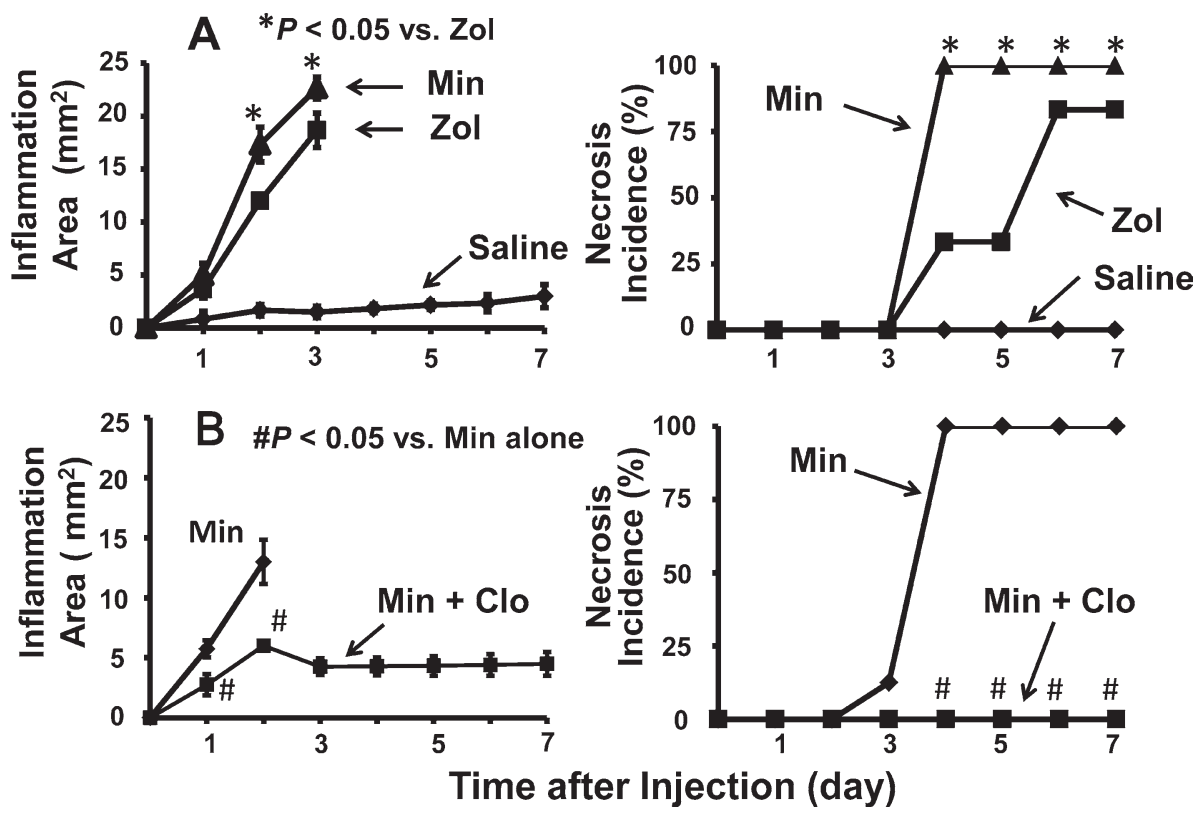

Fig. 5. Inflammatory and necrotic effects induced by subcutaneous injection of minodronate (Min) into ear pinnas, and the modulating effect of clodronate. (A) Saline, minodronate (Min, $2 \mathrm{mM}$ ), or zoledronate (Zol, $2 \mathrm{mM}$ ) was subcutaneously injected into the 8 ear pinnas of 4 mice $(20 \mu \mathrm{l} / \mathrm{ear})$, and inflammation and incidence of necrosis were measured (see Methods). (B) Saline, Min ( $2 \mathrm{mM})$, clodronate $(\mathrm{Clo}, 10 \mathrm{mM})$, or a mixture (Min + Clo; final concentrations $2 \mathrm{mM}$ and $10 \mathrm{mM}$, respectively), was subcutaneously injected into the 8 ear pinnas of 4 mice ( $20 \mu 1 /$ ear), and areas of inflammation and incidence of necrosis were measured. Each value for inflammation represents the mean \pm S.D. $(n=8)$.

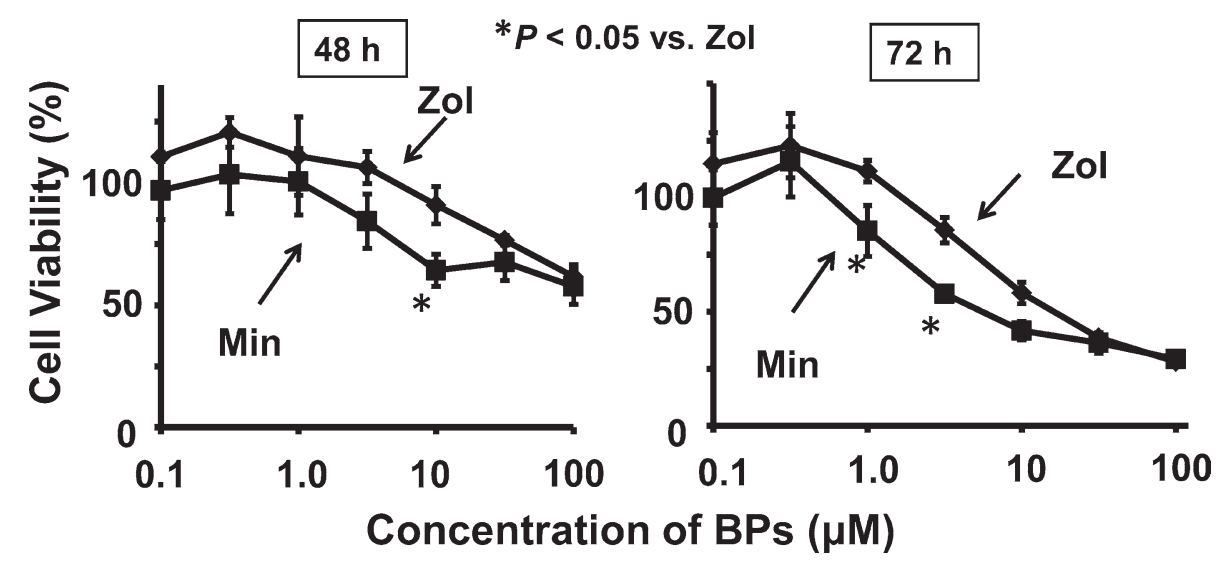

Fig. 6. Comparison of in vitro cytotoxic effects between minodronate (Min) and zoledronate (Zol). HPDL cells were incubated with minodronate or zoledronate at the indicated concentrations for 48 or $72 \mathrm{~h}$. Cell viability was evaluated by WST-8 assay. Data are given as mean \pm S.D.

In addition, it should be noted that because of the high affinities for bone hydroxyapatite, BPs, irrespective of whether they are N-BPs or non-N-BPs, accumulate in large amounts upon repeated administration. This accumulation is augmented in jawbones that already exhibit inflammation, an effect observed in both humans (Yamaguchi et al. 2010) and mice (Oizumi et al. 2010). Thus, as pointed out by Yamaguchi et al. (2010), it is very likely that the jawbone-accumulated N-BPs are released during the course of an infection and/or during tooth extraction, and that the released N-BPs directly injure the surrounding soft tissues. Indeed, Scheper et al. (2009) detected zoledronate in saliva collected from patients treated with this drug, indicating that N-BPs are indeed released from jawbones after accumulating therein. In the present study in mice, the INSE of minodronate was comparable to or greater than that of zoledronate, the N-BP with the highest ONJ risk yet reported (Woo et al. 2006). It has also been reported that minodronate directly injures gastric tissues upon oral injection in 24-h fasted rats, and that this effect is greater than those of alendronate and risedronate (Amagase et al. 2011). Hence, if minodronate is indeed released after its accumulation within jawbones, the released minodronate might directly injure the surrounding soft-tissues. 
Protective effect of clodronate (a non- $N$-BP) against minodronate-induced INSES

ONJ cases are very scarce in patients treated with nonN-BPs (clodronate and etidronate) (Crépin et al. 2010), although it is not clear whether these non-N-BPs have any INSEs, such as those of N-BPs. Concerning the INSEs of N-BPs in mice, we have reported that clodronate and etidronate can reduce or prevent the systemic and local INSEs of various N-BPs (Endo et al. 1999; Funayama et al. 2005; Oizumi et al. 2009, 2010; Shikama et al. 2010). In the present study, clodronate prevented the INSEs of minodronate, too, suggesting that the protective effect of clodronate is widely exerted against the INSEs of various N-BPs. In contrast, the ABRE induced by combined administration of clodronate with minodronate was greater than that of minodronate alone, a result similar to those obtained previously with combinations of clodronate and other N-BPs (Monma et al. 2004; Oizumi et al. 2009). On the basis of these findings, we propose that clodronate could be usefully employed as a combination drug with minodronate, as well as with other N-BPs, the aim being to prevent the necrotic action of the N-BP while retaining, or even enhancing, its ABRE.

\section{Involvement of IL-1 in inflammatory effects of $N-B P S$}

As previously observed with other N-BPs [alendronate, incadronate, and ibandronate; Endo et al. (1999)], we found that a number of inflammatory effects of intraperitoneally injected zoledronate and minodronate were significantly weaker in IL-1-KO mice than in control WT BALB/ c mice. This suggests a common involvement of IL-1 in the inflammatory effects of N-BPs. Although Deng et al. (2006) found that alendronate did not induce any detectable elevation in the serum level of IL-1 (or mature IL-1), we later reported that alendronate stimulates the synthesis of pro-IL-1 (but not mature IL-1) in macrophages (Shikama et al. 2010). We have also shown that the elevation of serum IL-1 levels induced by lipopolysaccharide (a surface component of gram-negative bacteria) is greatly augmented by alendronate (Sugawara et al. 1998; Yamaguchi et al. 2000). Taken together, these findings suggest that N-BPs may prime various tissues to release large amounts of mature IL-1 in the presence of inflammatory stimuli, leading to augmented inflammation and/or necrosis.

\section{Conclusion}

The results obtained in the present study suggest that minodronate has both an ABRE and INSEs comparable to or greater than those of zoledronate, the N-BP with the most powerful $\mathrm{ABRE}$ and highest ONJ risk yet reported. If this holds true in humans, minodronate, like other N-BPs, may be associated with INSEs in clinical use, and should therefore be used cautiously in patients. Even if that is the case, it may be possible to reduce or prevent the INSEs of minodronate, while retaining its powerful ABRE, by combined administration with clodronate. If, on the other hand,
INSEs do not become apparent during the future clinical use of minodronate, studies exploring the reason (i.e., for this difference between minodronate and other N-BPs) may provide important clues as to the cause of, and/or mechanisms underlying, the INSEs currently occurring in human patients during treatment with N-BPs.

\section{Acknowledgements} script.

We are grateful to Dr. Robert Timms for editing the manu-

\section{Funding}

This work was supported by grants from Tohoku University (Sendai, Japan) and the Japan Society for the Promotion of Science (21390529, 20592318, and 21890019).

\section{Conflict of Interest}

None of the listed authors has any financial or other interest that could be of conflict.

\section{References}

Adami, S., Bhalla, A.K., Dorizzi, R., Montesani, F., Rosini, S., Salvagno, G. \& Lo Cascio, V. (1987) The acute phase response after bisphosphonate administration. Calcif. Tissue Int., 41, 326-331.

Adami, S. \& Zamberlan, N. (1996) Adverse effects of bisphosphonate. A comparative review. Drug Saf., 14, 158-170.

Amagase, K., Inaba, A., Senta, T., Ishikawa, Y., Nukui, K., Murakami, T. \& Takeuchi, K. (2011) Gastric ulcerogenic and healing impairment effects of risedronate, a nitrogencontaining bisphosphonate in rats. Comparison with alendronate and minodronate. J. Physiol. Pharmacol., 62, 609-618.

Chen, J.S. \& Sambrook, P.N. (2012) Antiresorptive therapies for osteoporosis: a clinical review. Nature Rev. Endocrinol., 8, 81-91.

Crépin, S., Laroche, M.L., Sarry, B. \& Merle, L. (2010) Osteonecrosis of the jaw induced by clodronate, an alkylbisphsophonate: case report and literature review. Eur. J. Clin. Pharmacol., 66, 547-554.

Deng, X., Yu, Z., Funayama, H., Shoji, M., Sasano, T., Iwakura, Y., Sugawara, S. \& Endo, Y. (2006) Mutual augmentation of the induction of the histamine-forming enzyme, histidine decarboxylase, between alendronate and immuno-stimulants (IL-1, TNF, and LPS), and its prevention by clodronate. Toxicol. Appl. Pharmacol., 213, 64-73.

Endo, Y., Nakamura, M., Kikuchi, T., Shinoda, H., Takeda, Y., Nitta, Y. \& Kumagai, K. (1993) Aminobisphosphonates, potent inhibitors of bone resorption, induce a prolonged stimulation of histamine synthesis and increase macrophages, granulocytes and osteoclasts in vivo. Calcif. Tissue Int., 52, 248-254.

Endo, Y., Shibazaki, M., Yamaguchi, K., Nakamura, M. \& Kosugi, H. (1999) Inhibition of inflammatory actions of aminobisphosphonates by dichloromethylene bisphosphonate, a nonaminobisphosphonate. Br. J. Pharmacol., 126, 903-910.

Frith, J.C., Mönkkönen, J., Auriola, S., Mönkkönen, H. \& Rogers, M.J. (2001) The molecular mechanism of action of the antiresorptive and antiinflammatory drug clodronate. Arthritis Rheum., 44, 2201-2210.

Funayama, H., Ohsako, M., Monma, Y., Mayanagi, H., Sigawara, S. \& Endo, Y. (2005) Inhibition of inflammatory and boneresorption-inhibitory effects of alendronate by etidronate. Calcif. Tissue Int., 76, 448-457.

Geddes, A., D’Souza, S.M., Ebetino, F.H. \& Kenneth, J.I. (1994) 
Bisphosphonates: structure-activity relationships and therapeutic implications. In Bone and Mineral Research, vol. 8, edited by Heershe, N.M. \& Kanis, J.K., Elsevier Science BV, Amsterdam, Holland, pp. 265-306.

Hagino, H., Shiraki, M., Fukunaga, M., Nakano, T., Takaoka, K., Ohashi, Y., Nakamura, T. \& Matsumoto, T. (2011) Three years of treatment with minodronate in patients with postmenopausal osteoporosis. J. Bone Miner. Metab., 30, 439-446.

Horai, R., Asano, M., Sudo, K., Kanuka, H., Suzuki, M., Nishihara, M., Takahashi, M. \& Iwakura, Y. (1998) Production of mice deficient in genes for interleukin(IL)- $1 \alpha$, IL- $1 \beta$, IL- $1 \alpha / \beta$, and IL- 1 receptor antagonist shows that IL- $1 \beta$ is crucial in turpentine-induced fever development and glucocorticoid secretion. J. Exp. Med., 187, 1463-1475.

Kakimoto, S., Nagakura, Y., Tamura, S., Watabiki, T., Shibasaki, K., Tanaka, S., Mori, M., Sasamata, M. \& Okada, M. (2008) Minodronic acid, a third-generation bisphosphonate, antagonizes purinergic $\mathrm{P} 2 \mathrm{X}_{2 / 3}$ receptor function and exerts an analgesic effect in pain models. Eur. J. Pharmacol., 589, 98-101.

Monma, Y., Funayama, H., Mayanagi, H. \& Endo, Y. (2004) Effects of weekly administrations of alendronate + clodronate on young mouse tibia: localized action at the proximal growth plate. Calcif. Tissue Int., 74, 115-121.

Nemoto, E., Kanaya, S., Minamibuchi, M. \& Shimauchi, H. (2005) Cleavage of PDGF receptor on periodontal ligament cells by elastase. J. Dent. Res., 84, 629-633.

Neville-Webbe, H.L. \& Coleman, R.E. (2010) Bisphosphonates and RANK ligand inhibitors for the treatment and prevention of metastatic bone disease. Eur. J. Cancer, 46, 1211-1222.

Oizumi, T., Funayama, H., Yamaguchi, K., Yokoyama, M., Takahashi, H., Yamamoto, M., Kuroishi, T., Kumamoto, H., Sasaki, K., Kawamura, H., Sugawara, S. \& Endo, Y. (2010) Inhibition of necrotic actions of nitrogen-containing bisphosphonates (NBPs) and their elimination from bone by etidronate (a Non-NBP): a proposal for possible utilization of etidronate as a substitution drug for NBPs. J. Oral Maxillofac. Surg., 68, 1043-1054.

Oizumi, T., Yamaguchi, K., Funayama, H., Kuroishi, T., Kawamura, H., Sugawara, S. \& Endo, Y. (2009) Necrotic actions of nitrogen-containing bisphosphonates (NBPs) and their inhibition by clodronate (a non-NBP) in mice: potential for utilization of clodronate as a combination drug with an NBP. Basic Clin. Pharmacol. Toxicol., 104, 384-392.

Okazaki, R., Hagino, H., Ito, M., Sone, T., Nakamura, T., Mizunuma, H., Fukunaga, M., Shiraki, M., Nishizawa, Y., Ohashi, Y. \& Matsumoto, T. (2011) Eficacy and safety of monthly oral minodronate in patients with involutional osteoporosis. Osteoporosis Int., 23, 1737-1745.

Räikkönen, J., Crockett, J.C., Rogers, M.J., Mönkkönen, H., Auriola, S. \& Mönkkönen, J. (2009) Zoledrononic acid induces formation of a pro-apoptic ATP analogue and isopen- tenyl pyrophosphate in osteoclasts in vivo and in MCF-7 cells in vitro. Br. J. Pharmacol., 157, 427-435.

Roelofs, A.J., Thompson, K., Gordon, S. \& Rogers, M.J. (2006) Molecular mechanisms of action of bisphosphonates: current status. Clin. Cancer Res., 12 (20 Suppl), 6222s-6230s.

Rogers, M.J., Crockett, J.C., Coxon, F.P. \& Mönkkönen, J. (2011) Biochemical and cellular mechanisms of action of bisphosphonates. Bone, 49, 34-41.

Ruggiero, S., Mebrotra, B., Rosenberg, T.J. \& Engroff, S.L. (2004) Osteonecrosis of the jaws associated with the use of bisphosphonates: a review of 63 cases. J. Oral Maxillofac. Surg., 62, 527-534.

Schenk, R., Eggli, P., Fleisch, H. \& Rosini, S. (1986) Quantitative morphometric evaluation of the inhibitory activity of new aminobisphosphonates on bone resorption in the rat. Calcif. Tissue Int., 38, 342-349.

Scheper, M.A., Badros, A., Salama, A.R., Warburton, G., Cullen, K.J., Weikel, D.S. \& Meiller, T.F. (2009) A novel bioassay model to determine clinically significant bisphosphonate levels. Support. Care Cancer, 17, 1533-1557.

Shikama, Y., Nagai, Y., Okada, S., Oizumi, T., Shimauchi, H., Sugawara, S. \& Endo, Y. (2010) Pro-IL-1 $\beta$ accumulation in macrophages by alendronate and its prevention by clodronate. Toxicol. Lett., 199, 123-128.

Sugawara, S., Shibazaki, M., Takada, H., Kosugi, H. \& Endo, Y. (1998) Contrasting effects of an aminobisphosphonate, a potent inhibitor of bone resorption, on lipopolysaccharideinduced production of interleukin-1 and tumour necrosis factor $\alpha$ in mice. Br. J. Pharmacol., 125, 735-740.

Urade, M. (2010) Present condition of occurrence of osteonecrosis of the jaws related to bisphosphonate therapy. Nippon Koukugekagaku Zasshi, 56, 294-297 (abstract in English).

Woo, S.B., Hellstein, J.W. \& Kalmar, J.R. (2006) Systematic review: bisphosphonates and osteonecrosis of the jaws. Ann. Intern. Med., 144, 753-761.

Yamaguchi, K., Motegi, K., Iwakura, Y. \& Endo, Y. (2000) Involvement of interleukin-1 in the inflammatory actions of aminobisphosphonates in mice. Br. J. Pharmacol., 130, 16461654 .

Yamaguchi, K., Oizumi, T., Funayama, H., Kawamura, H., Sugawara, S. \& Endo, Y. (2010) Osteonecrosis of the jawbones in 2 osteoporosis patients treated with a nitrogencontaining bisphosphonate: osteonecrosis reduction replacing NBP with non-NBP (etidronate) and rationale. J. Oral Maxillofac. Surg., 68, 889-897.

Yu, Z., Funayama, H., Deng, X., Kuroishi, T., Sasano, T., Sugawara, S. \& Endo, Y. (2005) Comparative appraisal of clodronate, aspirin and dexamethasone as agents reducing alendronate-induced inflammation in a murine model. Basic Clin. Pharmacol. Toxicol., 97, 222-229. 